\title{
Problemli Çevrimiçi Oyun Kullanımı Ölçeği Türkçe Formu: Geçerlik ve Güvenirlik Çalışması
}

\author{
Ahmet AKIN ${ }^{1}$ \\ M. Emin TURAN ${ }^{2}$ \\ Ümran $\mathrm{AKIN}^{3}$
}

Öz: Bu çalışmanın amacı Problemli Çevrimiçi Oyun Kullanımı Ölçeği’ni Türkçeye uyarlamak ve geçerlik ve güvenirliğini incelemektir. Araştırmaya 110 kız ve 192 erkek olmak üzere toplam 302 üniversite öğrencisi katılmıştır. Doğrulayıcı faktör analizinde beş boyutlu (öfori, sağlık problemleri, çatışma, kontrol kaybı, sanal ilişkileri tercih etme) modelin yeterli uyum verdiği görülmüştür (birinci düzey; $x^{2}=607.67, \mathrm{sd}=157$, RMSEA $=.098, \mathrm{NFI}=.95$, $\mathrm{NNFI}=.95, \mathrm{IFI}=.96, \mathrm{CFI}=.96, \mathrm{RFI}=.84$, ikinci düzey; $x^{2}=690.18, \mathrm{sd}=161$, $\mathrm{RMSEA}=.099, \mathrm{NFI}=.87, \mathrm{NNFI}=.88, \mathrm{IFI}=.90, \mathrm{CFI}=.90, \mathrm{RFI}=.84)$. Problemli Çevrimiçi Oyun Kullanımı Ölçeği’nin Cronbach alfa iç tutarlık güvenirlik katsayıları alt boyutlar için sırasıyla “.92, .74, .87, .88, .84”; ölçeğin bütünü için ".94” olarak bulunmuştur. Ölçeğin düzeltilmiş madde toplam korelasyon katsayılarının “.46 ile .76” arasında değiştiği görülmektedir. Bu sonuçlar, Problemli Çevrimiçi Oyun Kullanımı Ölçeği’nin Türkçe formunun geçerli ve güvenilir bir ölçme aracı olarak değerlendirilebileceğini göstermektedir.

1 Doç. Dr. Sakarya Üniversitesi Psikolojik Danışmanlık ve Rehberlik Bölümü, Sakarya. aakin@sakarya.edu.tr

2 Uzman Psikolojik Danışman, MEB. mehmeteminturan@gmail.com

3 Yard. Doç. Dr. Sakarya Üniversitesi Psikolojik Danışmanlık ve Rehberlik Bölümü, Sakarya.uakin@sakarya.edu.tr 
Anahtar sözcükler: Problemli çevrimiçi oyun, Geçerlik, Güvenirlik, Doğrulayıcı faktör analizi

\section{GÍRIŞ}

Son yıllarda teknolojinin baş döndürücü hızının özellikle insanla ilgili her alana etki ettiğine şahitlik etmekteyiz. Kuşkusuz bilgisayar, bilgisayar oyunu ve internet teknolojileri de bu baş döndürücü hızdan etkilenmektedir (Seok \& DaCosta, 2014). Günümüzde internet kullanımı; iletişim kurmak, akademik araştırma yapmak, bilgiye ulaşmak ve eğlenmek için vazgeçilemez bir araç durumundadır (Frangos, Frangos, \& Sotiropoulos, 2011). İnternet kullanımı artık büyük bir çoğunluğun gündelik hayatında büyük bir yer tutmaktadır. Örnek vermemiz gerekirse e-mail, MSN, blog, Facebook ve Twitter vasıtasıyla arkadaşlarımızla dijital yoldan daha yakın bir bağlantı içerisindeyiz. Gün geçtikçe daha sık bir şekilde interneti eğlence, eğitim, seyahat, alışveriş yapma, tıbbi tavsiye arama, oyun oynama için kullanmaktayız. Bütün bu imkânlara hızlı bir şekilde erişebilmemiz için sadece bir bilgisayarımızın veya akıllı telefonumuzun olması yeterli olmaktadır (Zhan \& Chan, 2012).

Günümüzde teknolojik gelişmeler neticesinde cep telefonları vasıtasıyla bile bilgisayar oyuncuları kıtalar-arası müsabakalar gerçekleştirebilmektedirler. İnternetin bilgisayar oyunu ve çevrimiçi oyunlar dünyasına girmesiyle birlikte dünyanın her tarafından milyonlarca çevrimiçi oyun kullanıcısı iletişim kurarak birbirleriyle vakit geçirmektedir. Basit grafiklere sahip çevrimiçi oyunlardan en gelişmiş grafiklere ve altyapıya sahip çevrimiçi oyunlar, yazılı ve sesli sohbet imkânı sağlayarak çevrimiçi oyun kullanıcılarının bu oyunlara bağlanma ve bağımlı olma düzeylerini arttırabilmektedir (Seok \& DaCosta, 2014).

Çevrim içi oyunlar, bilgisayar oyunu (tek bilgisayar üzerinden oynanan oyunlar) ve internet oyunu olarak iki farklı şekilde sınıflandırılabilmektedir. İnternet oyunları ise web oyunu, network oyunu ve interaktif çevrimiçi oyun biçiminde sınıflandırılabilmektedir. Çevrimiçi oyunlarda bireyler diğer oyuncularla etkileşim kurarak rekabet içine girebilmektedir. Tek kişinin oynadığı bilgisayar oyunlarının aksine 
çevrimiçi oyunlar sosyal etkileşime izin vermektedir. Çevrimiçi oyunlarda; diğer oyuncularla sohbet etme, karşılıklı savaşma ve birlikte görevleri tamamlama imkânı vardır (Kim \& Kim, 2010). Bu durum çevrimiçi oyun bağımlılığının diğer oyun bağımlılığı türlerine göre daha çok yaygınlaşma potansiyeline sahip olduğunu gözler önüne sermektedir.

Çevrimiçi oyun platformu, en hızlı gelişen oyun sektörü konumundadır. Çevrimiçi oyunlar, büyük ve küçük gruplarla ve farklı zaman aralıklarında oynanabilmektedir. Çevrimiçi küçük gruplarla oynanan oyunlara çevrimiçi satranç oyununu örnek verebiliriz. Bu oyun tarzı iki kişi ile oynanabilmektedir ve göreceli olarak kısa sürmektedir. Büyük gruplarla oynanan oyunları ise yüzlerce hatta binlerce kişi oynayabilmektedir. Bu oyun grubu devasa çok oyunculu çevrim içi rol yapma oyunu (massively multi-player online role-playing game) olarak da bilinmektedir (Williams \& Skoric, 2005).

Bilgisayar oyunlarının devasa çok oyunculu çevrim içi rol yapma oyunu çeşidi günümüzde oldukça popülerdir. Bu oyunlarda dünyanın çeşitli coğrafyalarından kullanıcılar oyun karakterlerini geliştirmeye çalışırken gerçek zamanlı müsabakalar/savaşlar yapmaktadırlar (Northrup \& Shumway, 2014). Hem küçük hem de büyük oyunlarla oynanan çevrimiçi bilgisayar oyunları, toplumun özellikle de genç nüfusun büyük ilgisini çekmektedir.

Bilgisayar oyunlarının popülerliği ve gittikçe belli topluluklar tarafından benimsenmesi kamuoyu ve bilimsel toplulukların dikkatini çekmiştir. Bu oyunların bireylerin gündelik yaşamları ve iyi oluş düzeylerine, olumlu ve olumsuz etkilerini konu alan gittikçe artan çok sayıda araştırma vardır (Billieux ve diğerleri, 2015). Problemli bilgisayar oyunu kullanımıyla ilgili araştırmalar, bireyin yaşamının diğer yönlerini ihmal etmesi ve olumsuz sonuçların meydana gelmesi endişesi nedeniyle de artmıştır (Kirby, Jones, \& Copello, 2014).

Problemli çevrimiçi oyun kullanımını internet bağımlılığının bir değişkeni olarak ele almak mümkündür. Problemli çevrimiçi oyun kullanımı, kompulsif internet kullanımının en yaygın çeşidi olarak düşünülebilir. Bireylerin psikolojik ve fiziksel sağlıklarını ihmal ettikleri halde 
çevrimiçi oyun oynama alışkanlıklarından kurtulmalarının gittikçe zorlaştığını gösteren birçok araştırma bulguları mevcuttur (Charlton, 2002; Hellman, Schoenmakers, Nordstrom, \& van Holst, 2013; Kim, Namkoong, Ku, \& Kim, 2008; Ng \& Wiemer-Hastings, 2005; van Rooij, Schoenmakers, van de Eijnden, \& van de Mheen, 2010). Hatta problemli internet kullanımının cinayetlere dahi sebep olduğu ifade edilmiştir. Birçok devlet bilgisayar oyunlarının uygun olmayan içeriklerine erişimi engelleyebilmek için çalışmalar yapmasına rağmen bu konuda kanuni düzenleme yapan sadece birkaç devlet vardır (Zhan \& Chan, 2012).

Günümüzde bilgisayar oyunları ile ilgili araştırmalar ölçekler ve laboratuar/gözlem yoluyla gerçekleştirilmektedir (Williams \& Skoric, 2005). Araştırmacılar problemli çevrimiçi oyun kullanımını değerlendirmek için birçok ölçme aracı geliştirmişlerdir (Kim ve Kim, 2010). Bununla birlikte ülkemizde Problemli Çevrimiçi Oyun Kullanımını değerlendiren bir ölçme aracı bulunmamaktadır. Kim ve Kim (2010) tarafından geliştirilen Problemli Çevrimiçi Oyun Kullanımı Ölçeğinin en güçlü yanı hem problemli online oyun kavramının Öfori, sağlık problemi, çatışma, kontrol kaybı ve sanal ilişki tercihi gibi beş önemli alt boyutunu ayrı ayrı değerlendirmeye hem de bu alt boyutlardan toplam bir puan vermeye olanak sunmasıdır. Bu nedenle bu çalışmanın amacı Problemli Çevrimiçi Oyun Kullanımı Ölçeği'ni (Kim \& Kim, 2010) Türkçeye uyarlamak ve geçerlik ve güvenirliğini incelemektir.

\section{YÖNTEM}

\subsection{Araştırma Grubu}

Ölçeğin Türkçe formunun geçerlik ve güvenirlik analizleri, yaşları 18 ile 25 arasında değișen ve 110'ı kız, 192'si erkek olmak üzere toplam 302 üniversite öğrencisi üzerinde yürütülmüştür.

\section{2. Ölçme Araçları}

Problemli Çevrimiçi Oyun Kullanımı Ölçeği (Kim ve Kim, 2010). Öfori, sağlık problemi, çatışma, kontrol kaybı ve sanal ilişki tercihi alt boyutlarını içeren ve 20 maddeden oluşan bu ölçme aracı 5’li Likert tipi 
bir derecelendirmeye (1 Hiç katılmıyorum- 5 Tamamen katılıyorum) sahiptir. Ölçeğin orijinalinin geliştirme çalışmaları 1422 öğrenci üzerinde yürütülmüştür. Yapı geçerliği için uygulanan doğrulayıcı faktör analizinde beş boyutlu modelin uyum indeksi değerleri: $x 2=882.228$, sd=160, RMSEA=.056, TLI=.93 olarak bulunmuştur. İç tutarlılık güvenirlik katsayıları öfori alt boyutu için .84, sağlık problemi alt boyutu için .78, çatışma alt boyutu için .81, öz-kontrol kaybı alt boyutu için .82 ve sanal ilişki tercihi alt boyutu için .87 olarak bulunmuştur.

\section{3 İşlem}

Öncelikle ölçeği uyarlamak için elektronik posta yoluyla izin alınmıştır. İlk aşamada ölçek üç öğretim üyesi tarafından önce Türkçeye çevrilmiş, daha sonra tekrar İngilizceye çevrilerek çeviri ile orijinal form arasindaki tutarlılık incelenmiş ve denemelik Türkçe form elde edilmiştir. Daha sonra ölçeğin denemelik Türkçe formu iki öğretim üyesi tarafından incelenmiştir. Birden fazla anlam içeren veya anlaşılamayan ifadeleri tespit edilmiştir. Üçüncü aşamada ise Türkçe form eğitim bilimleri anabilim dalında görev yapan iki öğretim görevlisi tarafından tartışılarak düzeltmeler yapılmış ve ölçeğe son şekli verilmiştir.

Problemli Çevrimiçi Oyun Kullanımı Ölçeği'nin yapı geçerliğinin incelenmesi amacıyla doğrulayıcı faktör analizi (DFA) uygulanmıştır. Problemli Çevrimiçi Oyun Kullanımı Ölçeği'nin güvenirliği iç tutarlık yöntemiyle, madde analizi ise düzeltilmiş madde-toplam korelasyonuyla incelenmiştir. Geçerlik ve güvenirlik analizleri için SPSS 17,0 ve LISREL 8.54 (Jöreskog \& Sorbom, 1996) programları kullanılmıştır.

\section{BULGULAR}

\subsection{Madde Analizi ve Güvenirlik}

Problemli Çevrimiçi Oyun Kullanımı Ölçeğininin maddelerinin ayırt etme gücünü belirlemek amacıyla madde analizi yapılmıştır. Yapılan analiz sonucunda, madde toplam korelasyon katsayılarının .46 ile .76 
arasında sıralandığı, görülmüştür. Problemli Çevrimiçi Oyun Kullanımı Ölçeği’nin iç tutarlılık güvenirlik katsayısı ölçeğin bütünü için .94, öfori alt boyutu için .92, sağlık problemi alt boyutu için .74, çatışma alt boyutu için .87, öz-kontrol kaybı altboyutu için .88, sanal ilişki tercihi alt boyutu için .84 olarak bulunmuştur. Bulgular Tablo 1'de sunulmuştur.

Tablo 1: Problemli Çevrimiçi Oyun Kullanımı Ölçeği’nin Düzeltilmiş Madde Toplam Korelasyon Katsayıları

\begin{tabular}{cccc}
\hline Madde No & rjx & Madde No & rjx \\
\hline 1 & .61 & 11 & .61 \\
2 & .67 & 12 & .68 \\
3 & .65 & 13 & .76 \\
4 & .68 & 14 & .70 \\
5 & .46 & 15 & .75 \\
6 & .48 & 16 & .71 \\
7 & .59 & 17 & .68 \\
8 & .67 & 18 & .62 \\
9 & .71 & 19 & .53 \\
10 & .68 & 20 & .59 \\
\hline
\end{tabular}

\subsection{Yapı Geçerliği}

Problemli Çevrimiçi Oyun Kullanımı Ölçeğinnin yapı geçerliği için ölçeğin orijinal formunda bulunan faktörlerin doğrulanması amaciyla birinci ve ikinci düzey DFA uygulanmıştır. Birinci düzey DFA için elde edilen uyum indeksleri $\left(x^{2}=607.67, \mathrm{sd}=157, \mathrm{RMSEA}=.098, \mathrm{NFI}=.95\right.$, $\mathrm{NNFI}=.95, \mathrm{IFI}=.96, \mathrm{CFI}=.96, \mathrm{RFI}=.84)$ beş boyutlu Problemli Çevrimiçi Oyun Kullanımı Ölçeğinin yeterli düzeyde uyum verdiğini ortaya koymuştur. Ancak, 1.-2., 14.-15., ve 16.-17. maddeler arasında ikili 
hata kovaryansları tanımlanmıştır. Doğrulayıcı faktör analizine ait faktör yükleri Şekil l'de sunulmuştur.

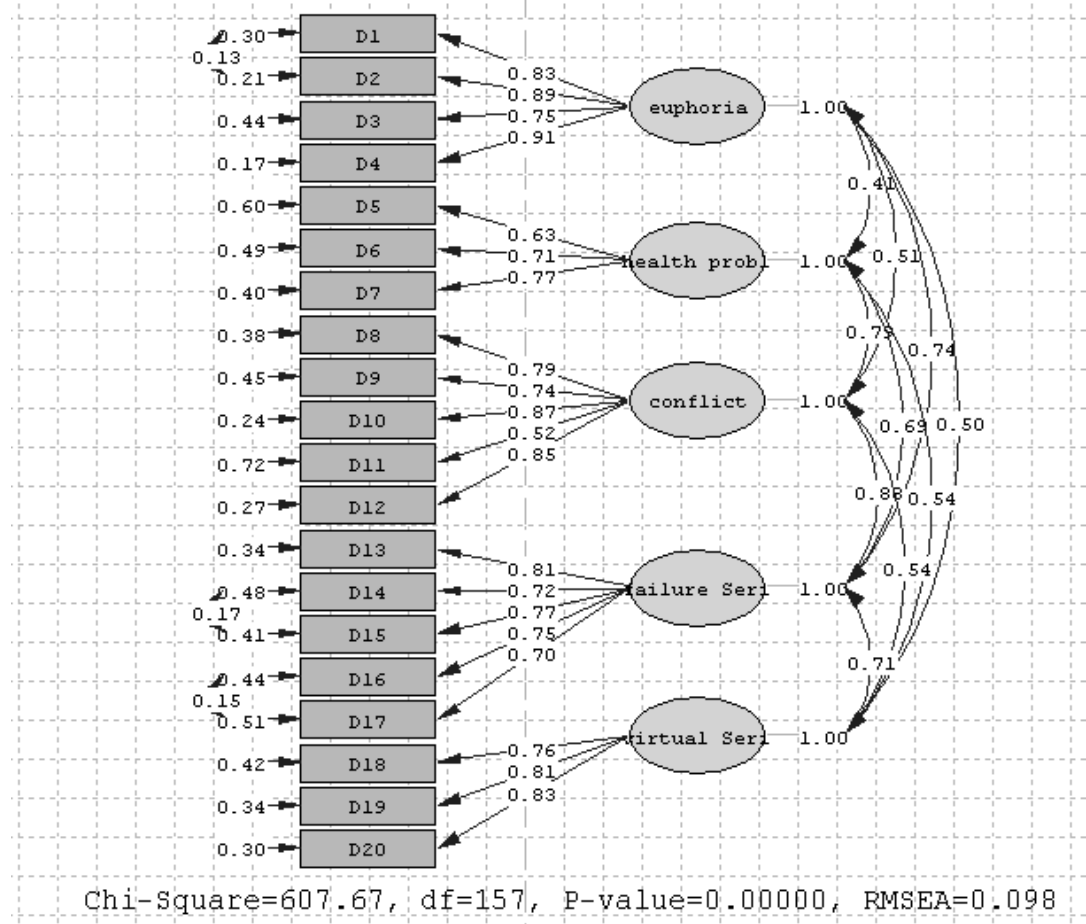

Şekil 1: Problemli Çevrimiçi Oyun Kullanımı Ölçeğinnin Doğrulayıcı Faktör Analizi

Ölçek toplam puan verdiği için ikinci düzey DFA da uygulanmış ve elde edilen uyum indeksleri $\left(x^{2}=690.18\right.$, sd $=161$, RMSEA $=.099$, NFI $=$ .87 , NNFI $=.88, \mathrm{IFI}=.90$, CFI $=.90$, RFI $=.84$ ) beş boyutlu Problemli Çevrimiçi Oyun Kullanımı Ölçeği’nin yeterli düzeyde uyum verdiğini ortaya koymuştur. Ancak, 1.-2., 10.-11., 14.-15. ve 13.-17. maddeler arasında ikili hata kovaryansları tanımlanmıştır. Doğrulayıcı faktör analizine ait faktör yükleri Şekil 2'de sunulmuştur. 


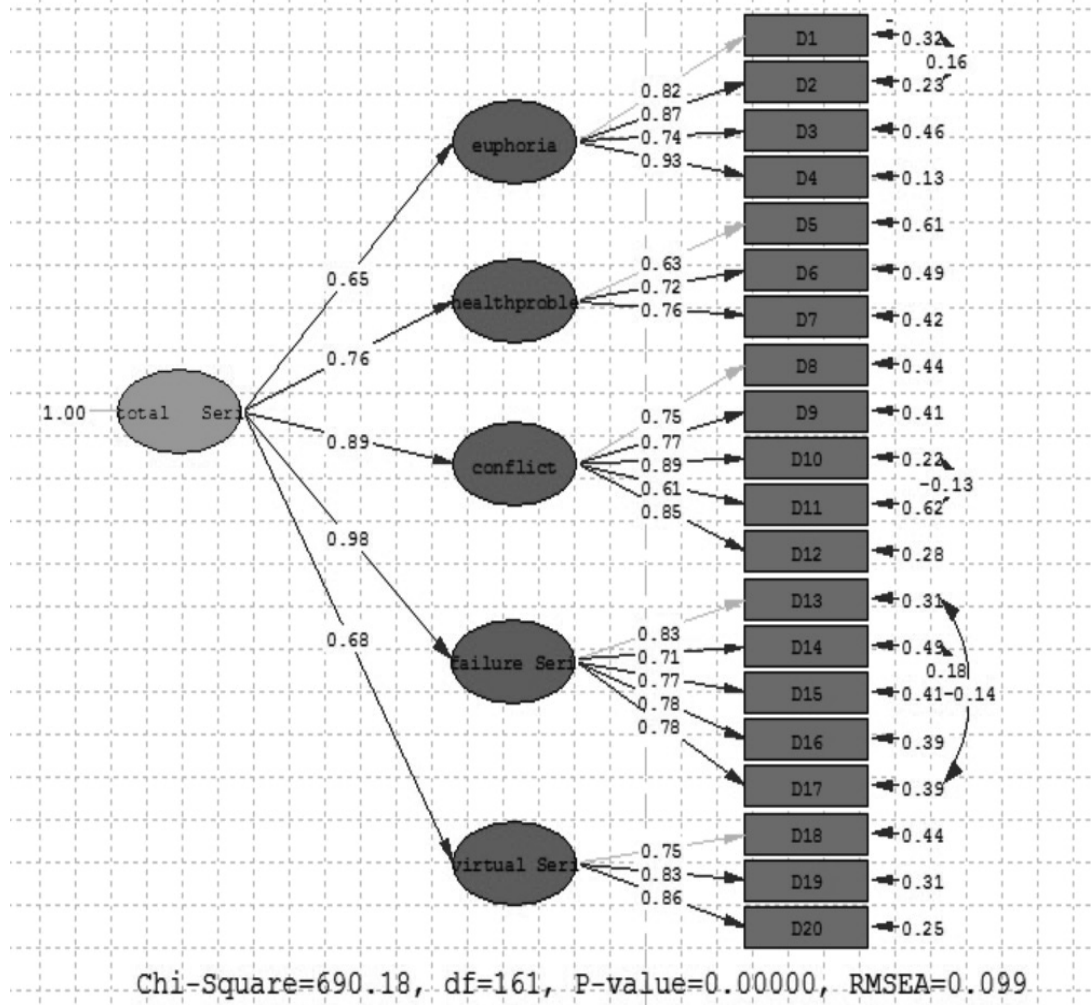

Şekil 2: Problemli Çevrimiçi Oyun Kullanımı Ölçeği'nin İkinci Düzey Doğrulayıcı Faktör Analizi

\section{YORUM/TARTIŞMA}

Bu çalışma Kim ve Kim (2010) tarafından geliştirilen Problemli Çevrimiçi Oyun Kullanımı Ölçeği'ni Türkçeye uyarlamak, geçerlik ve güvenirliğini incelenmek amaciyla gerçekleştirilmiştir. Geçerlik ve güvenirlik çalışmalarının yürütüldüğü gruplar sayı bakımından istatistiksel analizlerin gerektirdiği yeterliliktedir (Tabachnick \& Fidell, 2007). Problemli Çevrimiçi Oyun Kullanımı Ölçeği’nin yapı geçerliği DFA ile incelenmiştir. DFA için uyum indeksi sınırları göz önüne alındığında, modelin iyi uyum verdiği ve ölçeğin orijinal faktör yapısının Türkçe formun faktör yapısıyla uyuştuğu görülmektedir. Doğrulayıcı faktör 
analizi ile model-veri uyumuna ilişkin hesaplanan istatistiklerden en sık kullanılanları Ki-kare $\left(x^{2}\right), \mathrm{x}^{2} / \mathrm{sd}$, RMSEA, RMR, GFI ve AGFI'dir. Hesaplanan $x^{2} / \mathrm{df}$ oranının 5'ten küçük olması, GFI ve AGFI değerlerinin .90 'dan yüksek olması model-veri uyumunu göstermektedir (Marsh \& Hocevar, 1988). Bununla birlikte, GFI'nin .85'ten, AGFI'nin .80'den büyük çıkması, RMSEA değerlerinin .10'dan düşük çıkması, model veri uyumu için kabul edilebilir alt sınırlar olarak görülmektedir (Marsh, Balla, \& McDonald, 1988).

Problemli Çevrimiçi Oyun Kullanımı Ölçeği’nin güvenirlik katsayılarının yüksek bulunması, güvenirliğin yeterli düzeyde olduğunu göstermektedir. Araştırmalarda kullanılabilecek ölçme araçları için öngörülen güvenirlik düzeyinin .70 olduğu dikkate alınırsa, Problemli Çevrimiçi Oyun Kullanımı Ölçeği'nin güvenirliğini belirlemeye yönelik olarak elde edilen bulgular ölçeğin yeterli düzeyde güvenilir olduğunu ortaya koymuştur. Madde analizi sonucunda ölçeğin madde-toplam korelasyon katsayılarının .30 ölçütünü karşıladığı görülmüştür. Madde-toplam korelasyon katsayılarının yorumlanmasında .30 ve daha yüksek olan maddelerin, bireyleri ölçülen özellik bakımından iyi derecede ayırt ettiği göz önüne alındığında (Büyüköztürk, 2004), madde toplam korelasyon katsayılarının yüksek düzeyde olduğu görülmektedir.

Problemli Çevrimiçi Oyun Kullanımı Ölçeği ülkemizde özellikle de genç yetişkin gelişim gruplarında son derece yaygın bir sorun olan oyun bağımlılığını değerlendirmede işlevsel olarak kullanılabilecek bir ölçme aracıdır. Bu ölçme aracı, klinisyenler, psikologlar, okul danışmanları ve bağımlılık terapistleri tarafından kullanılabilir. Problemli Çevrimiçi Oyun Kullanımı Ölçeği Türkçe formunun; ülkemizde son derece hızla gelişen ve sinsi bir tehdit olarak gençlerimizin kitap okuma, spor ve müzikle ilgilenme ve kendilerini geliştirme gibi son derece önemli gelişimsel görevlerinin karşısında güçlü bir zehir olarak görülebilecek olan online oyun bağımlılı̆̆ın saptanmasında ve tedavi edilmesinde katkı sunacağ 1 umulmaktadır. 


\section{5. ÖNERILLER}

Problemli Çevrimiçi Oyun Kullanımı Ölçeği'nin geçerlik ve güvenirlik çalışmalarından elde edilen bulgulara göre ölçeğin kullanıma hazır olduğu ifade edilebilir. Ancak ölçeğin dilsel eşdeğerlik, test-tekrar test ve uyum geçerliğini inceleyecek araştırmalara da ihtiyaç duyulmaktadır. Ölçeğin geçerlik ve güvenirlik çalışmalarının yürütüldüğü araştırma grubu üniversite öğrencilerinden oluşmaktadır. Dolayısıyla ölçeğin farklı örneklemler üzerinde geçerlik güvenirlik çalışmalarının yapılması yerinde olacaktır. Ayrıca ölçeğin uyum geçerliğini belirlemek amacıyla oyun kullanımı ile diğer ilişkili kavramlar arasındaki bağlantılar da incelenebilir. Problemli Çevrimiçi Oyun Kullanımı Ölçeğinnin araştırmalarda kullanılmasının ölçme gücüne önemli katkılar sağlayacağı düşünülmektedir.

\section{Kaynakça}

Billieux, J., Thorens, G., Khazaal, Y., Zullino, D., Achab, S., \& der Linden, M.V. (2015). Problematic involvement in online games: A cluster analytic approach. Computers in Human Behavior, 43, 242-250.

Büyüköztürk, Ş. (2004). Veri analizi el kitabı. Ankara: Pegem A Yayıncılık.

Charlton, J. P. (2002). A factor-analytic investigation of computer 'addiction' and engagement. British Journal of Psychology, 93, 329-344.

Frangos, C. C., Frangos, C. C., \& Sotiropoulos, I. (2011). Problematic internet use among greek university students: an ordinal logistic regression with risk factors of negative psychological beliefs, pornographic sites, and online games. Cyberpsychology,Behavior, and Social Networking, 14(1-2), 51-58.

Hellman, M., Schoenmakers, T. M., Nordstrom, B. R., \& van Holst, R.J. (2013). Is there such a thing as online video game addiction? A crossdisciplinary review. Addiction Research and Theory, 21(2), 102-112.

Joreskog, K. G., \& Sorbom, D. (1996). LISREL 8 reference guide. Lincolnwood, IL: Scientific Software International. 
Kim, M. G., \& Kim, J. (2010). Cross-validation of reliability, convergent, and discriminant validity for the Problematic Online Game Use Scale. Computers in Human Behavior, 26, 389-398.

Kim, E. J., Namkoong, K., Ku, T., \& Kim, S. J. (2008). The relationship between online game addiction and aggression, self-control and narcissistic personality traits. European Psychiatry, 23, 212-218.

Kirby, A., Jones, C., \& Copello, A. (2014). The impact of massively multiplayer online role playing games (mmorpgs) on psychological wellbeing and the role of play motivations and problematic use. International Journal of Mental Health Addiction, 12, 36-51.

Marsh, H. W., \& Hocevar, D. (1988). A new more powerful approach to multitrait-multimethod analyses: Application of second-order confirmatory factor analysis. Journal of Applied Psychology, 73, 107-117.

Marsh, H. W., Balla, J. R., \& McDonald, R. P. (1988). Goodness-of-fit indexes in confirmatory factor analysis: The effect of sample size. Psychological Bulletin, 103, 391-410.

Ng, B. D., \& Wiemer-Hastings, P. (2005). Addiction to the internet and online gaming. Addiction, 8, 110-114.

Northrup, J. C., \& Shumway, S. (2014). Gamer widow: a phenomenological study of spouses of online video game addicts. The American Journal of Family Therapy, 42, 269-281.

Seok, S., \& DaCosta, B. (2014). Distinguishing addiction from high engagement: An investigation into the social lives of adolescent and young adult massively multiplayer online game players. Games and Culture, 9(4), 227-254.

Tabachnick, B. G., \& Fidell, L. S. (2007). Using multivariate statistics. Boston: Allyn and Bacon.

van Rooij, A. J., Schoenmakers, T. M., van de Eijnden, R. J. J. M., \& van de Mheen, D. (2010). Compulsive internet use: The role of online gaming and other internet applications. Journal of Adolescent Health, 47, 51-57. 
Williams, D., \& Skoric, M. (2005). Internet fantasy violence: A test of aggression in an online game. Communication Monographs, 72, 217-223.

Zhan, J. D., \& Chan, H.C. (2012). Government regulation of online game addiction. Communications of the Association for Information Systems, 30, 187-198.

$* * * * * * * * *$

Abstract: - Problematic Online Game Use Scale Turkish Form: The Study of Validity and Reliability-The aim of this research is to examine the validity and reliability of the Turkish version of the Problematic Online Game Use Scale (Kim \& Kim, 2010). Participants were 302 undergreduate students (110 were female and 192 were male). The results of confirmatory factor analysis indicated that the twenty items loaded on 5 factors (euphoria; health problem; conflict; failure of selfcontrol; and preference of virtual relationship: $\left(x^{2}=607.67, \mathrm{df}=157\right.$, RMSEA $=.098, \mathrm{NFI}=.95, \mathrm{NNFI}=.95, \mathrm{IFI}=.96, \mathrm{CFI}=.96, \mathrm{RFI}=.84$ for first order; $x^{2}=690.18, \mathrm{df}=161, \mathrm{RMSEA}=.099, \mathrm{NFI}=.87$, NNFI $=$ $.88, \mathrm{IFI}=.90, \mathrm{CFI}=.90, \mathrm{RFI}=.84$ for second order). The internal consistency coefficient of the scale was .94 . The corrected item-total correlations ranged from ".46 to 76 ". Overall findings demonstrated that this scale may be used as a valid and reliable instrument in order to assess problematic online game use level of individuals.

Key words: Problematic online game use, Validity, Reliability, Confirmatory factor analysis

\section{Summary}

The Internet technology has much impacted our lives. For example, we are more closely communicated with our friends in digital way (e.g. e-mail, MSN, blog, Facebook, Twitter). The internet technologies have used for learning, shopping, traveling, entertaining and seeking medical advice. We can gain Access to internet world if we have got only a 
computer or a smart phone (Zhan \& Chan, 2012). Online gaming is Internet addiction's a variant, especially in adolescents it is the most addictive of the forms of compulsive Internet use. There is growing proof of individuals finding it so hard to not use online game even though they would like to, frequently disregarding their psychological and physical health. (Charlton, 2002; Kim, Namkoong, Ku, \& Kim, 2008; Ng \& Wiemer-Hastings, 2005; Hellman, Schoenmakers, Nordstrom \& van Holst, 2013). Up to date, game researches have depend on basicly on two methods the survey and the laboratory or observational field experiment (Williams \& Skoric, 2005). Researchers have developed different measures to define problematic online game use (Kim \& Kim, 2010).

The present study was conducted on 302 university students. Primarily the Problematic Online Game Use Scale was translated into Turkish by three academicians. After that the Turkish form was back-translated into English and examined the consistency between the Turkish and English forms. Than Turkish form has been reviewed by two academicians from educational sciences department. Finally they discussed the Turkish form and along with some corrections this scale was prepared for validity and reliability analyses.

Confirmatory factor analysis (CFA) was executed to confirm the original scale's structure in Turkish culture. As reliability analysis and internal consistency coefficients and the item-total correlations were examined. The results of confirmatory factor analysis indicated that the twenty items loaded on five factors $\left(x^{2}=607.67, \mathrm{df}=157, \mathrm{RMSEA}=.098\right.$, NFI $=$ $.95, \mathrm{NNFI}=.95, \mathrm{IFI}=.96, \mathrm{CFI}=.96, \mathrm{RFI}=.84$ for first order; $x^{2}=690.18$, $\mathrm{df}=161, \mathrm{RMSEA}=.099, \mathrm{NFI}=.87, \mathrm{NNFI}=.88, \mathrm{IFI}=.90, \mathrm{CFI}=.90, \mathrm{RFI}=$ .84 for second order). The internal consistency coefficients of five subscales varied between .74 and .92, respectively. The corrected item-total correlations of Problematic Online Game Use Scale ranged from .46 to .76. Overall findings demonstrated that this scale may be used as a valid and reliable instrument in order to assess academic support level of individuals. Nevertheless, further studies that will use Problematic Online Game Use Scale are important for its measurement force. 
